\section{ESTÉTICA, FORMAÇÃO INICIAL E DANÇA: UM OLHAR PARA A FORMAÇÃO DE PROFESSORES DE EDUCAÇÃO FÍSICA}

\author{
AESTHETICS , INITIAL EDUCATION AND DANCE: A LOOK ON PHYSICAL \\ EDUCATION TEACHERS' TRAINING
}

STÉTICA, FORMACIÓN INICIAL Y DANZA: UNA MIRADA HACIA LA
FORMACIÓN DE PROFESORES DE EDUCACIÓN FÍSICA

Deizi Domingues da Rocha*, Ricardo Rezer**
Palavras chave:

Estética.

Educação.

Dança.

Docentes.

\begin{abstract}
Resumo: O propósito deste estudo teórico-bibliográfico foi aproximar os pressupostos da teoria estética adorniana e a dança no âmbito da formação inicial em Educação Física (EF). As contribuições da teoria estética para a formação de professores no campo da EF podem se dar, principalmente, pela possibilidade de qualificar um olhar mais sensível para a educação, através de uma reeducação dos sentidos permeada pela reflexão filosófica ligada à arte. A dança representa, então, uma possibilidade significativa de aproximação com a teoria estética, como possibilidade, inclusive, de dura crítica a uma deseducação dos sentidos.
\end{abstract}

\section{Keywords:}

Esthetics.

Education.

Dance.

Faculty.

Palabras clave:

Estética.

Educación.

Danza.

Docentes.
Abstract: The purpose of this theoretical and bibliographical study was to approach the assumptions of Adorno's aesthetic theory and dance in initial education in Physical Education (PE). The contributions of aesthetic theory to teacher training in PE can happen mainly through the possibility of a more sensitive look at education by re-educating the senses pervaded by philosophical reflection connected to art. Dance is a significant possibility for approximation to aesthetic theory, even with a possibility to make harsh criticism of miseducation of the senses.

Resumen: El propósito de este estudio teórico y bibliográfico fue aproximar los supuestos de la teoría estética de Adorno y la danza en la formación inicial en Educación Física $(E F)$. Las aportaciones de la teoría estética para la formación de profesores en el campo de la EF pueden darse sobre todo por la posibilidad de tener una mirada más sensible sobre la educación, a través de una reeducación de los sentidos mediada por la reflexión filosófica ligada al arte. La danza representa, entonces, una posibilidad significativa de aproximación a la teoría estética, como posibilidad, incluso, de dura crítica a la (des) educación de los sentidos.
*Programa de Pós-Graduação em Educação da Universidade Comunitária da Região de Chapecó. Chapecó, SC Brasil.

E-mail: deizirocha@unochapeco.edu.br

**Programa de Pós-Graduação em Educação da Universidade Comunitária da Região de Chapecó. Chapecó, SC, Brasil.

E-mail: rrezer@unochapeco.edu.br.

Recebido em: 25-11-2014

Aprovado em: 06-06-2015

(c) (1) (8) Licence 


\section{CONSIDERAÇÕES INICIAIS}

Este artigo é resultado de uma dissertação de mestrado desenvolvida no Programa de Pós-Graduação em Educação da Universidade em Educação da Universidade Comunitária da Região de Chapecó (Unochapecó) e insere-se no campo de discussões sobre formação de professores. Teve como objetivo aproximar os pressupostos da Teoria Estética adorniana e a dança, no âmbito da formação inicial em Educação Física (EF).

Para tal, partimos do pressuposto de que entender a EF como possibilidade de experiência estética é contribuir com a sua legitimação no campo da educação, intermediada pelos elementos da cultura corporal de movimento, como é o caso da dança. Diante disso, procuramos pensar a dança pela EF, através da interlocução com a Teoria Estética adorniana.

Abordar a formação inicial em EF é um convite para discutir e problematizar acerca das responsabilidades pedagógicas deste campo do conhecimento, tomando a educação superior como um importante e complexo lócus investigativo, entendendo a universidade como um centro privilegiado de produção e socialização do conhecimento.

Quando nos propomos a estudar a dança, nos referimos a ela enquanto conteúdo da/na $\mathrm{EF}$, que possibilita ao corpo-sujeito construções e significações para sua "formação humana", já que entendemos a dança enquanto um saber construído de/para formação e transformação social. Nesse aspecto, cabe destacar que a dança se caracteriza/encontra "dentro" da EF, enquanto elemento da cultura corporal de movimento. Porém, importante evidenciar que a dança não é "da" EF, mas se aproxima dela enquanto parte da cultura que interessa a este campo do conhecimento.

Tal perspectiva nos reporta aos estudos de Saraiva-Kunz (2003, p. 413), quando demonstra preocupação com os processos de formação dos professores e seus conhecimentos para trabalhar/atuar com dança. A autora acredita que "professores e professoras devem buscar uma aproximação com as discussões sobre a arte e a cultura", bem como devemos "estudar a dança, de seu centro para as suas fronteiras com a arte, a cultura e a educação".

Na direção de enfrentar os objetivos deste estudo, realizamos uma pesquisa descritiva, de caráter teórico-bibliográfico, a fim de aproximar os pressupostos da Teoria Estética adorniana e a dança, no âmbito da formação inicial em EF. Inicialmente, nos aproximamos da Teoria Estética adorniana através de uma leitura sistematizada, densa e tensa. Após, realizamos um levantamento de artigos, dissertações e teses que tratassem sobre 0 tema de forma direta ou tangencial. A busca por dissertações e teses foi realizada no Banco de Teses e Dissertações (BTD) da Coordenação de Aperfeiçoamento de Pessoal de Nível Superior (CAPES) e na Biblioteca Digital Brasileira de Teses e Dissertações (BDTD). Já a busca por artigos foi realizada nos periódicos do campo da Educação Física, classificados conforme estratos superiores de avaliação da Capes (A1, A2, B1 e B2). Para a busca, foram utilizadas as seguintes palavraschave: Teoria Estética adorniana, Formação Inicial em Educação Física e Dança.

Através disso, considerando os objetivos da pesquisa, selecionamos dez teses e seis dissertações para análise. No que se refere aos periódicos, selecionamos 13 artigos A2; três artigos B1 e sete artigos B2. Em todos eles foram identificados: autor, título, ano e o resumo. A aproximação com essas produções foi através da leitura dos resumos e, consequentemente, através do aprofundamento teórico e elaboração de sínteses para que pudessem ser 
incorporadas ao texto. Por questões de espaço, neste artigo nos deteremos menos neste aspecto e mais nos argumentos e sínteses derivadas do processo metodológico de análise da obra de Adorno Teoria Estética.

A fim de torná-lo mais didático, subdividimos este artigo em três momentos, todos interligados entre si. Inicialmente, produzimos uma abordagem sobre o sentido da estética, conduzindo a discussão para a Teoria Estética adorniana. Em um segundo momento, abordamos a formação de professores a partir das contribuições desta teoria. Finalmente, aproximamos a discussão para a formação no campo da EF, compreendendo a dança como tema privilegiado para aproximações com a estética.

\section{SOBRE A ESTÉTICA: APROXIMAÇÕES COM O TEMA}

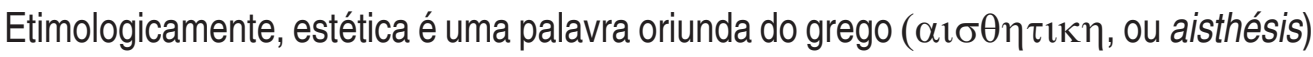
e significa percepção, sensação, sensibilidade. Segundo Barilli (apud SANTAELLA, 2000, p. 9): "[...] a raiz grega aisth, no verbo aisthanomai, quer dizer sentir, não com o coração ou com os sentimentos, mas com os sentidos, rede de percepções físicas". No contemporâneo, esse termo é bastante utilizado para designar várias "coisas", no entanto, de maneira específica, ele se encontra entremeado na história da filosofia.

Sobre isso, cabe destacar Baumgarten (1735), que escreveu um texto intitulado Reflexões filosóficas sobre algumas questões pertencentes à poesia. A partir desse momento a estética foi tratada como a ciência da percepção em geral'. Posteriormente, o autor escreve Aesthetica, e a ciência da percepção passa a ser tomada como sinônimo de conhecimento através dos sentidos, "[...] a perfeição da cognição sensitiva que encontra na beleza o seu objeto próprio". (COHEN; GUYER apud SANTAELLA, 2000, p. 9). Baumgarten buscava que a estética fosse a perfeição do conhecimento sensível, com a tarefa de cultivá-lo, e não dominá-lo.

A difícil tarefa de estudar a obra Teoria Estética de Theodor W. Adorno está explícita nas palavras de muitos outros que a adotaram como fonte interlocutora ou alicerce para seus estudos $^{2}$. As insuficiências da organização da obra, devido à morte prematura do autor, bem como as repetições que incidem ao longo do texto, revelam parte das dificuldades encontradas no decorrer da leitura e da análise. Outro fator importante a ser considerado nessa trajetória se refere às ideias expressas no texto, que ora tomam como ponto referencial a década em que Adorno ensinou sobre estética, ora encontram-se com momentos mais recentes, devido à própria temporalidade na organização da obra.

Contudo, ressaltamos que o diálogo com a obra está pautado nas possibilidades de sua aproximação com o objetivo central deste estudo, ou seja, aproximar os pressupostos da Teoria Estética adorniana e a dança no âmbito da formação inicial em EF. Para tal, não buscamos revelar o "verdadeiro" pensamento do autor, mas nos aproximar de sua obra, na condição de interlocutores, como possibilidade norteadora da reflexão que nos propomos.

Nesse sentido, a aproximação com a obra Teoria Estética nos remeteu à preocupação com o caminho que a arte vem trilhando. A complexidade da obra representa uma provocação

\footnotetext{
1 Ao abordar Estética, é importante considerar também as contribuições de outro alemão, Johann Joachim Winckelmann (1717-1768) contemporâneo de Baumgarten, considerado por muitos como o "Pai" da história da arte, com significativas influências na discussão sobre estética (ROBINSON apud REZER, 2014). 
de reflexão que nos causou significativa inquietação e incômodo. Ao mesmo tempo, de certa forma, nos causava conforto, ao nos apresentar possibilidades de reflexões para 0 processo de formação, mesmo se tratando de uma teoria não específica para a educação. Cabe salientar que o tom adorniano de escrita está pautado em uma tradição denominada de Teoria Crítica ${ }^{3}$.

A reflexão estética para esse autor provém da sua relação com a arte, principalmente a música, na sua intimidade com os processos de criação e apreciação da arte erudita. No entanto, a experiência de Adorno com arte, ou seja, não somente com música, mas a literatura e outras formas artísticas, Ihe credencia de certa forma a uma abordagem madura, que nos possibilita refletir para além de uma forma de arte, e nos permite transitar nas mais variadas formas artísticas como fontes de experiência de mundo.

Nessa direção, a Teoria Estética adorniana nos convida para um esforço significativo, a fim de explorar a dimensão estética do humano através de um saber sensível, nos propondo um encontro do próprio "eu" (experiência vivida) com a realidade (realidade vivida), promovendo novas formas de conhecimento sob o critério da sensibilidade. A proposta de Adorno possibilita tecer um encontro do sujeito consigo próprio por outros caminhos, que a racionalidade talvez não dê conta. E é nesse momento que a estética, a experiência estética, ingressa como possibilidade proeminente na e para a formação de corpos-sujeitos. Contudo é necessário que o sujeito tenha uma formação para reflexão crítica que lhe possibilite pensar por conta própria e, ainda, que aprenda a reconhecer as contradições presentes no mundo no qual vivemos.

Pensar o processo de formação, de sensibilização dos corpos-sujeitos, é pensar nos atores que lidam com a arte de educar, ou seja, o docente. No entanto, o docente também é "educado" no que se refere à preparação para atuar, e o processo de formação docente também pode ser entendido dentro de um pensar o sentido do sensível na ação pedagógica, isso porque entendemos que ser professor é construir-se professor num processo dialético cotidiano.

Para Adorno, existem condições básicas para ser professor, e uma delas é que ele tenha uma formação ampla, que denomina de "formação cultural" (Bildung), que, segundo Jaehn (2005, p. 109), "[...] é a ideia de uma formação integral do ser humano". Baseados nisso, nos propormos a utilizar as reflexões de Adorno como interlocutor na discussão sobre estética e educação. $O$ sentido proposto foi de explorarmos caminhos para a sensibilização das ações do homem através da formação pelos sentidos humanos, ou seja, uma formação pelo sensível que considera a contradição e a resistência como elementos fundamentais para o comportamento crítico de si e do outro.

Neste encontro, a EF, enquanto campo do conhecimento inserida na educação, também vem se preocupando com questões que abarquem a formação de sujeitos críticos e reflexivos na realidade que os envolve, em que as experiências estéticas podem ir se delineando através do fazer pedagógico docente. No próximo tópico, abordaremos de forma direta este tema.

3 Em síntese, trata-se de uma tradição teórica que pretende se contrapor à teoria tradicional, de influência cartesiana. Associada à Escola de Frankfurt (Instituto para Pesquisa Social), tem como representantes Max Horkheimer, Theodor Adorno, Herbert Marcuse, Jurgen Habermas, entre outros. Atualmente, o Instituto para Pesquisa Social, ligado à Universidade de Frankfurt, tem como diretor o filósofo e sociólogo alemão Axel Honneth. 


\section{A FORMAÇÃO DE PROFESSORES: CONTRIBUIÇÕES DA TEORIA ESTÉTICA ADORNIANA}

O princípio de formação defendido por Adorno pauta-se na liberdade, mas entendese também que "[...] nada do que, de fato, se chame formação poderá ser apreendido sem pressupostos". (ADORNO, 1996, p. 390). Uma liberdade fundamentada e aprofundada, portanto relativa. Por um lado, não podemos simplesmente aceitar as coisas como dadas, mas, sim, resistir às ideias e confrontá-las em busca de uma formação cultural ampliada, na medida em que isso perpetrar sentido aos envolvidos. Por outro lado, devemos ficar atentos à crítica de Adorno sobre a obliteração do indivíduo frente à educação de massa. Vejamos a seguir.

\footnotetext{
Uma educação sem indivíduos é opressiva, repressiva. Mas quando procuramos cultivar indivíduos da mesma maneira que cultivamos plantas que regamos com água, então isto tem algo de quimérico e de ideológico. A única possibilidade que existe é tornar tudo isso consciente na educação [...]. Eu diria que hoje o indivíduo só sobrevive enquanto núcleo impulsionador da resistência. (ADORNO, 1995, p. 154).
}

Ao trazer esses argumentos para a discussão na formação inicial, entendemos que, ao mesmo tempo em que nos colocamos a favor de uma formação cultural ampliada, Adorno (1996) nos propõe um colocar-se contra ela. Nessa perspectiva, a formação requer um olhar de consideração e de cuidado para formação cultural que se dá em todas as partes. Ao mesmo tempo, deve ser um olhar cuidadoso para o como acolher estas, partindo de um princípio que nos formamos a cada momento, frente à diversidade, idealismos, incoerências e à falta de sensibilidade. Para Adorno (1996, p. 410) "[...] a única possibilidade de sobrevivência que resta à cultura é a auto-reflexão crítica sobre a semiformação, em que necessariamente ela se converteu".

Devemos considerar que a formação inicial é um contexto que apresenta necessidade e características próprias, mas que pode, de acordo com Rezer (2014), ser um espaço que construa um olhar mais alargado sobre o mundo tanto para os estudantes como para os professores. No campo da EF, como nos sugere o autor, uma formação que seja profissional, pessoal, cultural, musical, artística, erudita, técnica, enfim, uma formação humana que amplie a percepção humana de mundo e possibilite a autonomia intelectual no exercício da docência.

Uma possibilidade é pensarmos no processo de formação inicial de professores 0 "lugar" da estética, da arte, em meio a tantos desafios que os currículos nos apresentam. Outra é procurar pensar de forma crítica e reflexiva os diferentes saberes que edificam nossa prática pedagógica e que nos dão condições de nos formarmos culturalmente. Sem dúvidas, nesta direção, a estética adquire status de grande envergadura.

O professor formador tem o papel de problematizar, transformar e ressignificar o que 0 educando traz e produz para/na vida. Porém, a formação inicial, muitas vezes, não dá conta de problematizar e explorar a si mesma, a ponto de provocar no outro a emancipação e a busca por autonomia.

Certamente, o professor necessita de uma base teórica que fundamente seu conhecimento, ou melhor, justifique a sua ação (prática pedagógica), pois "a nossa ação está em dependência do nosso conhecimento, onde há uma teorização que a suporta, assim, devemos pensar ações para que sejam produtos de nossa escolha e não de determinação" (FENSTERSEIFER, 2009, p. 4). 
[...] o conhecimento é aquilo que fica e nos permite dialogar com o universo da prática, onde, conforme eu olho essa produção de conhecimento, esta me leva a um tipo de compreensão, o critério de conhecimento é uma referência, ou seja, o conhecimento baliza o modo como eu encaminho a prática pedagógica, o modo de fazer é o modo que eu penso. (FENSTERSEIFER, 2009, p. 4).

A prática pedagógica deve estar imbuída de conhecimentos que nos possibilitarão validarmos nossos saberes na experiência pedagógica, ou seja, potencializar nossas ações e, bem mais do que isso, refletir acerca delas. Nesse caso, refletir concretamente sobre as contribuições de uma discussão estética no processo de formação de professores de EF representa um salto. Especialmente se considerarmos a forte vinculação deste campo com as ciências naturais. Se o sujeito que se movimenta experimenta sua realização em diferentes dimensões, aprender a perceber a dimensão estética não se trata de pouca coisa. Reconhecêla como fundamental para sua atuação docente, que aborda pedagogicamente manifestações da cultura corporal de movimento, denota uma experiência indispensável, que se manifesta como uma possibilidade de qualificar sua intervenção, bem como de elevar a sensibilidade a uma dimensão humana imprescindível para a atuação docente neste campo.

Porém, não se aprende ou se ensina somente pela experiência. Lembrando Adorno (2012, p. 529), somente a experiência não é suficiente, pois é necessário que seja alimentada pelo pensamento crítico. Levar a sério este referencial nos faz projetar que a experiência estética não se ensina e se aprende somente pelo pensamento, mas pelo encontro sensível com o mundo, o que nos permite reelaborar nossa própria leitura de mundo, tendo a experiência estética como pressuposto nevrálgico para a formação de professores de EF. O desafio nada simples que nos cabe é qualificar esta discussão ao longo do próprio processo formativo.

As contribuições da Teoria Estética para a formação de professores no campo da EF pode se dar em diversos aspectos, principalmente em um olhar mais sensível para a educação, que permita desenvolver a autonomia do sujeito, através de uma reeducação dos sentidos permeada pela reflexão filosófica ligada à arte. Concordando com Marins (2012, p. 70) quando diz que "[...] a arte apoiada pela filosofia tem o poder de resgatar o indivíduo da sociedade promovendo uma articulação entre sentidos e reflexão".

Assim, problematizar o processo de formação de professores e a Teoria Estética é um desafio significativo e uma tarefa extremamente complexa a ser enfrentada, especialmente no campo da EF. Para isso, partimos do pressuposto de que é necessário perspectivar a formação a partir da noção de uma formação ampliada (Bildung).

Nesse caso, ao tomarmos a EF enquanto prática pedagógica que produz diferentes conhecimentos permeados pela cultura corporal de movimento, nos aproximamos da questão estética como uma possibilidade sensível de mundo, na qual formas racionalizadas não conseguem alcançar - por exemplo, aquilo que sentimos na realização ou na apreciação de uma experiência de movimento.

Podemos atribuir a formação como um saber plural que se desenha ao longo da vida dos sujeitos, ou seja, pelos saberes oriundos da formação profissional e pessoal, de saberes disciplinares, curriculares e experienciais que serão "recrutados" na prática pedagógica. Reconhecer isso é reconhecer que a formação de professores não se pauta exclusivamente por uma racionalidade técnica instrumental, tendo em vista que os professores em processo de formação podem ter acesso a outras experiências, como a experiência estética. 
Reconhecer as possibilidades de uma discussão estética no âmbito da EF representa um movimento inicial para pensarmos a formação de professores neste âmbito. Assim, de acordo com Adorno (2012, p. 530), quem "[...] apenas permanece no interior, a arte não the abrirá os olhos; quem unicamente fica no exterior, falsifica as obras de arte por uma falta de afinidade". Então, a tensão entre dentro e fora, entre estranhamento e familiaridade, nos abre portas que devem ser consideradas como possibilidades para a formação de professores. A estética representa nessa discussão, um olhar para si (corpo-sujeito), que permita ampliar nossa capacidade de reconhecer dimensões para além da racionalidade. Esforço bem de acordo com as diferentes e complexas dimensões do humano, como, por exemplo, o que se aprende com o corpo pela percepção sensível do mundo.

Adorno nos ajuda a compreender a arte num contexto social, bem como a questionar a importância que damos a ela. Provoca-nos a refletir no por que a arte fica em segundo plano para a formação humana. Nesse sentido, a Teoria Estética adorniana representa uma possibilidade na formação de professores quando critica a deseducação dos sentidos. Quando entende que ela também é uma possibilidade de reeducação sensível, através da reflexão filosófica alicerçada pela arte, como nos diz Adorno. Concordando com ele, a arte e a filosofia aliadas possibilitam o empoderamento do sujeito por intermédio do conhecimento, da crítica e da reflexão, mas tomando como referência, também, a dimensão sensível.

A estética abre, assim, uma possibilidade de refletir sobre a formação em suas diferentes dimensões (cultural, política, ética, entre outras) - uma educação dos sentidos em prol de uma formação crítica. A ideia é enriquecer o repertório cultural do professor, como possibilidade de que ele possa transcendê-lo durante o seu fazer docente. Ou seja, uma formação na qual educamos a sensibilidade para o reconhecimento.

Ao nos preocuparmos com os caminhos da educação e, portanto, da própria formação, percebemos possibilidades de relações entre sujeito e obra, matéria e espírito, que vão se desdobrando no pensar e no ser, no sentir e no agir. Nesse caso, a aproximação com a estética permite edificar novas perspectivas (críticas) para a formação de professores, tema que será tratado de forma mais específica a seguir.

\section{FORMAÇÃO EM EF: A DANÇA COMO TEMA PRIVILEGIADO PARA APROXIMAÇÕES COM A ESTÉTICA}

A estética está na dança como a doçura está no mel. (BERTICELLI)4.

Quando falamos em dança a partir da EF, buscamos uma reflexão sobre um entendimento de dança de forma questionadora e para além de uma forma meramente objetiva (SARAIVA-KUNZ, 2003, p. 106). A ideia é ressaltar que seu significado deve ser incluso numa esfera que observe questões como o contexto, o tempo, o espaço e as diferentes teorias que a constituem. Nesse sentido, "a dança pode ser compreendida como uma outra forma de ser e estar no mundo". Assim, a autora nos convida a compreender esta outra maneira de estar no mundo, discutindo aspectos do próprio relacionamento do ser consigo mesmo, nas relações não objetivas entre o ser e o espaço, o tempo e a expressividade, ressaltando, desta forma, a importância da sensibilidade.

4 Nesta epígrafe, nos valemos de mais uma das contribuições significativas do professor Dr. Ireno Antônio Berticelli, membro da banca avaliadora. 
Ao nos debruçarmos sobre os estudos de dança e sua influência no processo educacional, nos deparamos com algumas problemáticas, entre elas, o fato de como a dança acontece enquanto prática educativa produtora de sentidos e significados tanto para o docente como para o corpo-sujeito que dança (no caso desta investigação, do professor em processo de formação). Refletir acerca da dança e sua possibilidade estética, pretendendo entendê-la como linguagem, arte e educação, permite aflorar um diálogo pautado na sensibilidade dos sentidos do "ser" humano. Perceber suas relações com a prática educativa no processo de formação inicial em EF é de suma relevância, visto que a dança pode ser compreendida como um conteúdo da EF no processo de formação de professores. Assim, o trato com a dança requer uma reflexão filosófica (e pedagógica), enquanto arte, expressão e prática educativa, que necessariamente passa pelo campo da estética.

As contribuições da estética no campo educacional vêm crescendo de forma lenta, mas significativa, isso porque começamos a entender e buscar nas reflexões filosóficas espaços de trocas e respostas para muitas ações educativas, como é o caso da dança. De tal modo, pensar dança, educação e estética é entrelaçar reflexões que vão enveredando rumo à filosofia, ou melhor, é refletir filosoficamente a humanidade e sua comunicação. Essa tríade pode promover experiências sensiveis que consideram o ser humano na sua intimidade consigo próprio e com o coletivo, construindo saberes (tanto racionais como sensíveis) através da força expressiva de ser quem é sem deixar de lado a realidade de mundo.

Entender a dança, conforme Kleinubing (2012, p. 176), é percebê-la como "[...] uma educação capaz de nos sensibilizar para a beleza de todos os corpos", em que o processo de sensibilização do ser permite um posicionamento crítico perante a realidade. Assim, as experiências sensíveis em dança estão diretamente relacionadas com a prática educativa, pela vivência do se-movimentar, pelo despertar dos sentimentos e das sensações através da tomada de consciência como um novo sentido de formação humana.

É importante frisar que não desconsideramos a dança e suas diferentes possibilidades de intervenção em diferentes contextos, mas salientamos a necessidade de darmos à dança 0 trato que merece enquanto linguagem e conteúdo da EF, que está inserido em um currículo e que deve vislumbrar a formação como um espaço de ensinar e aprender essa linguagem.

Partindo desta contextualização e apontamentos sobre a importância da dança enquanto conteúdo da EF, levantamos alguns questionamentos: será que a dança tem espaço objetivo nos cursos de formação em EF? Os saberes, os valores histórico-sociais e educativos da dança são reconhecidos pelos docentes e discentes? Será que as universidades têm privilegiado os saberes estéticos e artísticos? Como se organizam e se desenvolvem os programas que (em tese) lidam com esse conhecimento? Qual a leitura que o egresso faz sobre suas experiências com dança na formação inicial em EF? Estas e outras questões são de suma importância para discutirmos a dança na EF, pois deve, de acordo com Ugaya (2011, p. 44) "[...] ser discutida e repensada para que os preconceitos e estereótipos que permeiam sua existência sejam rompidos e superados".

Aqui fica clara a necessidade de novas investigações que se proponham a adentrar essa problemática, tendo em vista a complexidade dos assuntos dela derivados. Sem dúvidas, pensar esta discussão na formação inicial reporta, ainda, muitos desafios a serem enfrentados. 
Contudo, a formação inicial em EF pode influenciar a forma de atuação do professor com ensino da dança, ou seja, a sua prática educativa. O processo de formação deve levar em conta que o estudante, para além de saber dançar, deve entender e saber o porquê de ensinar a dança (dimensão racional), e também abrir possibilidades para sentir a dança enquanto possibilidade estética do mundo humano (dimensão estética). A dança faz parte da parcela da cultura corporal de movimento que interessa ao campo da EF, e os professores devem estar preparados para "lidar" com e a partir dela.

Nesse caso, assumir a dança como tema privilegiado para a aproximação com a estética é uma investida significativa no que tange às diferentes possibilidades do se-movimentar com sentido e significado. Porém, para além da abordagem aqui retratada, a dança é uma possibilidade enquanto um dos conteúdos da EF na formação inicial. Ou seja, os demais conteúdos, as demais disciplinas, também podem (devem) tratar desta discussão, desde que reconheçam nela sentido e possibilidade. Ampliar a compreensão sobre as possibilidades de aproximação com a estética pode ampliar nossa capacidade de lidar com a arte da docência também pela dimensão do sensível.

Para discutir e refletir sobre a dança na formação inicial em EF, faz-se necessário entender que o processo de formação é o foco principal para "desamarrar os nós" que, ao chegar à universidade, o estudante traz consigo - uma bagagem histórica e cultural edificada ao longo de sua vida, algo que não pode ser esquecido ou deixado de lado pelo processo de formação, mas refletido, revisitado e transformado pela própria formação. Desta forma, aprender o quê, como e para quê ensinar a dança é de suma relevância, mas, como nos diz Ugaya (2011, p. 142),

[...] isto não basta. Para saber ser professor é preciso muito mais que teorias, técnicas, competências, fazer uso de tecnologias. Para se fazer professor é preciso ter sensibilidade: sentir, ouvir, admirar, pausar, respirar. [...] Entender que vivemos em um mundo de contradições, do inacabamento, da infinitude e das mil e uma possibilidades. [...] Os conhecimentos ensinados e aprendidos em todo e qualquer ambiente educativo devem estimular a construção de novos sentidos para a vida, consequentemente, novas perspectivas sobre e para 0 mundo. Novas nuances, novos porquês, novas cores, novos desejos, novas sensibilidades [...].

Acreditamos que estudar o fenômeno da dança por meio da experimentação do sabersentir pelo se-movimentar é investir no seu potencial formador, é nos aproximarmos de uma formação humano-artístico-cultural. É provocar discussões de arte e cultura para além das paredes, muros, livros, entre outros. É sentir na "pele" o processo como um todo, ou seja, de formar-se professor pela possibilidade de ser e estar sensível às coisas e a si mesmo. É permitir a dança para além-fronteira com a arte, o movimento, a cultura, a vida, a educação. É a capacidade de pensar, sentir, agir e refletir sobre a realidade através das experiências vividas.

A dança na formação deve preocupar-se em preparar os futuros professores para um posicionamento crítico diante da realidade (e a estética assume a condição de uma possibilidade). Aqui, a dança significa um processo de sensibilização do fazer docente e do próprio docente. É um formar-se através do critério da sensibilidade, permeado pelas diferentes experimentações do ser-estar sensível. Nesse caso, entendemos a dança enquanto possibilidade na formação inicial de discutir e refletir conhecimentos por meio da experimentação estética - conhecimentos que são racionais, mas também emocionais. Mas talvez esse conteúdo da EF, esta arte, consiga 
explorar aquilo que a racionalidade exclusivamente não dá conta, e que, ao não conseguirmos descrever, que possamos, como afirma Adorno, dar mais importância ao que não se percebe na obra do que aquilo que se percebe.

A dança como uma prática estética, de acordo com Kleinubing (2009, p. 12-13), "[...] possibilita a materialização da sensibilidade humana, ampliando a capacidade expressiva e, no contexto educativo enquanto elemento da cultura de movimento promove a instauração de um espírito crítico". A dança, vista numa dimensão estética, é tomar a ideia de que ela se constitui como resistência radical frente à semicultura, perspectivando a tensão derivada da investida na dimensão estética em um espaço e tempo racionalizados, tais como a universidade.

Nessa perspectiva, a dança se configura enquanto manifestação humana possível de modificações e inserção de novos conhecimentos baseando-se nas experiências e possibilidades de cada "ser". Portanto, o processo de formação inicial para o trabalho com a dança no campo da EF pode ser visto e vivido também enquanto experiência estética que, através da leitura de mundo, de forma crítica e reflexiva, possa estabelecer significativas percepções pautadas pelo critério da sensibilidade, como o educar para si e para o outro, permeadas pelas tensões entre 0 sujeito e 0 objeto, nas contradições e nas resistências advindas das experiências e da produção do conhecimento que se desenha no processo de formação, nas práticas pedagógicas, nas trocas e nas experiências vividas enquanto seres humanos preocupados com processo de emancipação, autonomia e esclarecimento.

\section{CONSIDERAÇÕES FINAIS}

O "encontro" com Adorno e, mais precisamente, a sua Teoria Estética como fonte principal de interlocução deste estudo nos permitiram perceber que a teoria crítica ainda permanece "atual", desde que a tomemos com cuidado, tendo em vista sua condição de orientação críticoreflexiva para compreender o ser humano, a si mesmo e o mundo.

O diálogo proposto buscou apontar reflexões que possam nos auxiliar a pensar o processo de formação inicial em EF, amparado pelo critério da sensibilidade, através de outra forma de ser e estar no mundo, vislumbrando uma formação crítica para autonomia e emancipação dos corpos-sujeitos.

As contribuições da Teoria Estética para a formação de professores no campo da EF pode se dar em diversos segmentos, principalmente, em um olhar mais sensível para a educação, que permita desenvolver a autonomia do sujeito, através de uma reeducação dos sentidos permeada pela reflexão filosófica ligada à arte.

Diante disso, a proposta de tomar a dança nessa discussão parte de sua compreensão enquanto possibilidade que permeia diversas áreas do conhecimento e de atuação do ser humano, tal qual a educação. A Teoria Estética nos aproxima da dança na formação inicial em EF quando se caracteriza como uma dura crítica à deseducação dos sentidos, ao passo que a dança pode ser um estímulo para a reeducação sensível através das diferentes formas de experienciar o movimento dançante e da reflexão filosófica aliada à arte. A arte como possibilidade de reeducação sensível, ou seja, uma educação dos sentidos para a arte. Isso nos parece de suma importância como possibilidade emancipadora, algo nevrálgico para a formação inicial. 
A formação inicial em EF pautada nos pressupostos da Teoria Estética pode proporcionar uma formação humana que considere o ser humano enquanto autor e ator do processo do formar-se. Uma formação que seja artística, cultural, pessoal, profissional entre todas as denominações que podemos lançar, mas que seja, sobretudo, uma formação para emancipação do corpo-sujeito, o que se dá na formação inicial e não se esgota nela, deixando marcas que acompanham o sujeito ao longo da vida.

O risco de radicalizar esta discussão é tomar a estética como referência central de mundo, substituta da racionalidade, o que promoveria uma "estetização de mundo", algo paradoxal e contraditório frente às pretensões desta investigação. A ideia não é "estetizar" a formação, mas tomá-la considerando a dimensão sensível, entendendo-a como uma possibilidade de mundo, como uma reflexão sensível e crítica presente no processo de formação inicial docente.

Aproximar a Teoria Estética adorniana, a formação inicial em EF e a dança possibilita o encontro entre diferentes "artes", esforço que nos convida a explorar a dimensão estética do humano através de um saber sensível que perspectiva uma "grande obra de arte" (formação) alicerçada pela/na educação para o pensamento crítico que promova a emancipação dos sujeitos para/no mundo. Assim, percebemos que a dança na formação inicial em EF é uma possibilidade de pensar questões estéticas que sustentem uma discussão cultural de e para a formação humana no sentido amplo, que integre várias áreas do conhecimento de forma crítica e reflexiva, permitindo a criação de novos espetáculos no palco educacional através da emancipação para transformação da educação, da formação cultural e do mundo.

Tudo isso sem ilusões, pois conhecemos razoavelmente bem a realidade e os entraves atuais da educação, fato esse que nos leva a perceber o enfraquecimento de muitas das pretensões apontadas neste estudo. Talvez esse trabalho seja mais uma atitude estética que não se explica, que não se descreve, não se quantifica, mas que, para isso, talvez bastaria um passo... uma dança!

\section{REFERÊNCIAS}

ADORNO, Theodor Wiesengrund. Educação e emancipação. Tradução Wolfgang Leo Maar. Rio de Janeiro: Paz e Terra, 1995.

ADORNO, Theodor Wiesengrund. Teoria da semicultura (TS). Tradução de Newton Ramos-deOliveira, Bruno Pucci, Claudia B. Moura Abreu. Educação \& Sociedade, Campinas, v. 17, n. 56, p. 388-411, dez. 1996.

ADORNO, Theodor Wiesengrund. Teoria estética. Tradução de Artur Morão. Lisboa: Edições 70, 2012.

FARINON, Mauricio João. 0 ético e o estético em Adorno. Tese (Doutorado em Educação) Pontifícia Universidade Católica do Rio Grande do Sul, Porto Alegre, 2012.

FENSTERSEIFER, Paulo. Epistemologia e Prática Pedagógica. Revista Brasileira de Ciência do Esporte, Campinas, v. 30, n. 3, p. 203-214, maio 2009.

JAEHN, Lisete. Educação para a emancipação em Adorno. Passo Fundo: UPF, 2005. 
KLEINUBING, Neusa Dendena. A dança como espaço-tempo de intersubjetividades: possibilidade da educação física no ensino médio. Dissertação (Mestrado) - Centro de Desportos, Universidade Federal de Santa Catarina, Florianópolis, 2009.

KLEINUBING, Neusa Dendena. Projeto contradança: a extensão universitária dialogando com a dança e a diversidade. In: SARAIVA, Maria do Carmo; KLEINUBING, Neusa Dendena. (Org.). Dança: diversidade, caminhos e encontros. Jundiaí: Paco Editorial, 2012. p. 176.

MARINS, Alexandre Ricardo. Educar para o pensamento crítico: um estudo sobre a teoria de Adorno aplicada a educação. 2012. Dissertação (mestrado) - Pontifícia Universidade Católica de São Paulo, São Paulo, 2012.

REZER, Ricardo. Educação Física na educação superior: trabalho docente, epistemologia e hermenêutica. 1. ed. Chapecó: Argos Editora Universitária, 2014. (Coleção ABEU).

SANTAELLA, Lúcia. Estética: de Platão a Pierce. São Paulo: Experimento, 2000.

SARAIVA-KUNZ, Maria do Carmo. Dança e gênero na escola: formas de ser e viver mediadas pela educação estética. Tese (Doutorado) - Motricidade Humana, Universidade Técnica de Lisboa, Lisboa, 2003.

SCHAEFER, Sérgio. A teoria estética em Adorno. Tese (Doutorado) - Instituto de Letras, Universidade Federal do Rio Grande do Sul, Porto Alegre, 2012.

UGAYA, Andressa de Souza. A dança na formação docente em educação física. Tese (Doutorado) - Faculdade de Educação Física, Universidade Estadual de Campinas, Campinas, 2011. 